\title{
Dissipation of four insecticides in tomato fruit using high performance liquid chromatography and QuEChERS methodology
}

Gomaa Ramadan ${ }^{1}$, Mohamed Shawir ${ }^{1}$, Ahmed El-bakary ${ }^{1}$, and Samir Abdelgaleil ${ }^{1 *}$

\section{ABSTRACT}

Insecticides play an important role in increasing agricultural production, but their extensive use has led to environmental problems including health hazards to humans. The present study was carried out to investigate the residual levels and dissipation behavior of four insecticides, namely abamectin, thiamethoxam, spinosad, and chlorpyrifos, in tomato (Solanum lycopersicum L.) fruits under Egyptian field condition. The insecticide residues were determined after application of insecticides for three times at recommended rates. The extraction of insecticide residues was carried out by using QuEChERS method. The determination of residual levels was performed by high performance liquid chromatography coupled with diode array detector (HPLC-DAD). Recoveries were between $85 \%$ and $130 \%$, with relative standard deviations from $1.8 \%$ to $17.0 \%$ at two fortified levels. The dissipation rates of insecticides followed first-order kinetics $\left(C_{t}=0.2627 \mathrm{e}^{-0.17 t}, C_{t}=3.7183\right.$ $\mathrm{e}^{-0.275 \mathrm{t}}, \mathrm{C}_{\mathrm{t}}=0.1778 \mathrm{e}^{-0.407 \mathrm{t}}, \mathrm{Ct}=0.6074 \mathrm{e}^{-0.11 \mathrm{t}}$ for abamectin, chlorpyrifos, spinosad and thiamethoxam, respectively). The values of half-life of insecticides were 4.1, 2.5, 1.7 , and $6.3 \mathrm{~d}$ for abamectin, chlorpyrifos, spinosad and thiamethoxam, respectively. The results indicated that tomato fruits could be safely consumed after $7,15,<1$ and $10 \mathrm{~d}$ of application at recommended rates for abamectin, chlorpyrifos, spinosad and thiamethoxam, respectively, according to the recommended EU maximum residue limits (MRLs).

Key words: Abamectin, chlorpyrifos, residues, Solanum lycopersicum, spinosad, thiamethoxam.

${ }^{1}$ Alexandria University, Faculty of Agriculture, 21545-El-Shatby, Alexandria, Egypt.

"Corresponding author (samirabdelgaleil@gmail.com).

Received: 18 February 2015.

Accepted: 5 August 2015.

doi:10.4067/S0718-58392016000100018

\section{INTRODUCTION}

Tomato (Solanum lycopersicum L.) belongs to the Solanaceae family and is one of the most popular and widely grown vegetables in the world (Dorais et al., 2008). Tomato constitutes a basic component of human diet in many countries around the world. Egypt is the fifth largest tomato producer in the world (FAO, 2011). Egypt produces about seven million tons of tomato each year (Malhat et al., 2012).

Tomato crop in the Mediterranean Basin, including Egypt, and in Europe has been recently attacked by the tomato leafminer Tuta absoluta (Meyrick) (Lepidoptera: Gelechiidae). This insect is difficult to control due to its high reproduction rate and potential to develop resistance to insecticides. Nowadays, T. absoluta is a major pest of tomato in the Mediterranean countries. The insect was first detected in Spain in 2006, then in other countries such France, Morocco, Algeria, Egypt, Greece, and Malta (Urbaneja et al., 2007; Mohammed, 2010; Roditakis et al., 2010). It is estimated that the pest may cause loss up to $80 \%-100 \%$ in tomato crop production in both greenhouses and fields (Korycinska and Moran, 2009). In addition to T. absoluta, tomato crop in Egypt is attacked by a number of pests and diseases. Thus, more than 100 natural and synthetic pesticides belongs to different chemical groups have been authorized for use to control of different pests and pathogens (APC, 2010). Therefore, the residue analysis of pesticides in tomato fruits under field condition has to be monitored frequently (Fenoll et al., 2009).

The degradation and residual behaviors of insecticides after their application may be affected by many factors such as plant species, insecticide chemical structure, type of formulation, volatilization, application method, climate, and photodegradation (Garau et al., 2002). In the literature, there are several reports about the residues analysis of four insecticides (abamectin, chlorpyrifos, spinosad, and thiamethoxam) in different kinds of vegetables and their derivatives (Mandal et al., 2009; Mohapatra et al., 2010; Chen et al., 2012; Wang et al., 2013; Liu et al., 2013). In addition, few studies were reported on the residue analysis of chlorpyrifos and thiamethoxam in tomato fruits (Al-Eed, 2006; Abd El-Zaher et al., 2011; Gupta et al., 2011). However, there was a lack of studies reported on dissipation and residual behaviors of abamectin and spinosad in tomato fruits. In the present study, abamectin, spinosad, thiamethoxam and chlorpyrifos, were applied at recommended rates for control of T. absoluta to evaluate the 
dissipation, the residue levels, and the preharvest intervals for these insecticides in fruits of tomato grown under Egyptian field conditions.

\section{MATERIAL AND METHODS}

\section{Chemicals and solvents}

Technical grade insecticides (98\% purity) were supplied by Laboratory of Central Pesticides, Giza, Egypt, and Chema industries company El-Noubaria, Egypt. Methanol and acetonitrile were HPLC grade and purchased from Sigma (Sigma GmbH, Darmstadt, Germany). Primary secondary amine (PSA, $40 \mu \mathrm{m}$ Bondesil) and graphitized carbon black sorbent were purchased from Supelco (Supelco, Bellefonte, Pennsylvania, USA). Dispersive solid phase extraction (SPE) $2 \mathrm{~mL}$, fruits and vegetables purchased from Agilent (Santa Clara, California, USA). Analytical grade of anhydrous magnesium sulfate and sodium acetate were obtained from Carlo Erba (Rodano, Italy) reagents. Sodium chloride and ammonium acetate were purchased from Nasr Company (Alexandria, Egypt) and Lab-Scan Analytical Sciences (Gliwice, Poland), respectively.

\section{Field trials}

The research was conducted in 2013 at flood irrigated field at Banger El-Soker region, El Amreya $\left(31^{\circ} 10^{\prime} \mathrm{N}, 29^{\circ} 77^{\prime}\right.$ E), Alexandria, Egypt. The experiments were organized in a randomized complete block design. For each tested insecticide, three replicates were used. The area of each replicate or plot was $42 \mathrm{~m}^{2}$. The following commercial formulations: $18.6 \%$ abamectin $\left(152.4 \mathrm{~g} \mathrm{~L}^{-1}\right)+$ thiamethoxam (33.2 $\mathrm{g} \mathrm{L}^{-1}$ ) (Agri-Flex, Syngenta, Basel, Switzerland), $48 \%$ chlorpyrifos (Lirifos, Laaskem Ltd., Lilianton, South Africa), and 24\% spinosad (Tracer, Dow AgroSciences, Indianapolis, Indiana, USA) were sprayed on tomato foliage at the recommended rates; $95.0,1140.0$, and $17.0 \mathrm{~g}$ ai ha ${ }^{-1}$ for Agri-Flex, Lirifos, and Tracer, respectively, using knapsack sprayer (CP3). Three untreated tomato plots were used as control. The relative humidity during the application period was $67.0 \%$ and temperature was $36.5^{\circ} \mathrm{C}$.

\section{Sample collection and preparation}

Three tomato fruit samples (marketable size fruits), each $500 \mathrm{~g}$, were randomly taken from each treatment plot. The samples were collected at 0 ( $1 \mathrm{~h}$ after spray), 1, 3, 5, 7, 10, and $15 \mathrm{~d}$ after insecticide application. Control samples were also collected after each sampling time interval. The samples were transferred immediately to the laboratory in an ice box. The samples were homogenized and kept at $-20{ }^{\circ} \mathrm{C}$ in deep freezer until used for analysis.

\section{Extraction and clean up}

Chlorpyrifos and thiamethoxam. The tomato samples were extracted and cleaned up using QuEChERS methodology (acronym for quick easy cheap effective rugged safe) (Anastassiades et al., 2003). A homogenized tomato fruit sample $(15 \mathrm{~g})$ was taken in to a centrifuge tube $(50-\mathrm{mL})$. Fifteen milliliters of acetonitrile containing $1.0 \%$ acetic acid was transferred to the centrifuge tube and vigorously shaken for $1 \mathrm{~min}$. Then, $6 \mathrm{~g}$ magnesium sulfate anhydrous, $1.5 \mathrm{~g}$ sodium acetate were added, and then the mixture was shaken vigorously for $5 \mathrm{~min}$. The mixture was centrifuged at $3000 \mathrm{rpm}$ for $5 \mathrm{~min}$. One milliliter of the supernatant was transferred to centrifuge tube $(1-\mathrm{mL})$ and shaken with $50 \mathrm{mg}$ PSA, $25 \mathrm{mg}$ graphitized carbon black and $150 \mathrm{mg}$ magnesium sulfate. Thereafter, the tube was centrifuged for $10 \mathrm{~min}$ at $6000 \mathrm{rpm}$. The supernatant was taken for analysis by high performance liquid chromatography coupled with diode array detector (Agilent 1100 Series HPLC-DAD, Agilent Technologies, Santa Clara, California, USA).

Abamectin and spinosad. Tomato fruit samples were extracted and cleaned-up as previously described with small modifications. A homogenized tomato fruit sample (15 g) was taken into a centrifuge tube $(50-\mathrm{mL})$. Fifteen milliliters of acetonitrile containing $1.0 \%$ acetic acid was transferred to the centrifuge tube and vigorously shaken for $1 \mathrm{~min}$. Then, $6 \mathrm{~g}$ of magnesium sulfate anhydrous $(6 \mathrm{~g}$ sodium chloride in the case of spinosad) and $1.5 \mathrm{~g}$ sodium acetate were added, and then the mixture was shaken vigorously for 5 $\mathrm{min}$. The mixture was centrifuged at $3000 \mathrm{rpm}$ for $5 \mathrm{~min}$. Five milliliters of the supernatant was transferred to a new tube and evaporated to dryness, then re-dissolved in $1 \mathrm{~mL}$ acetonitrile and shaken with $75 \mathrm{mg}$ PSA, $25 \mathrm{mg}$ graphitized carbon black and $300 \mathrm{mg}$ anhydrous magnesium sulfate. Thereafter, the tube was centrifuged for $10 \mathrm{~min}$ at $6000 \mathrm{rpm}$. The supernatant was taken for analysis by HPLC system.

\section{Residue analysis of insecticides}

The analysis of insecticide residues was performed with highperformance liquid chromatography system equipped with a diode array detector (HPLC-DAD) and quaternary pump (HP-1100 Series, Agilent Technologies). The separation was achieved on a C18 column $(250 \times 4.6 \mathrm{~mm}, 5 \mu \mathrm{m})$. The mobile phase and detection wavelength of each insecticide are shown in Table 1.

\section{Statistical analysis}

The analytical determinations were made in triplicate for each sampling on three field block samples. The dissipation rate constant and half-life were calculated using first-order rate equation: $C_{t}=C_{0} e^{-k t}$, where $C_{t}$ is the insecticide residue at the time $t, C_{0}$ is the initial deposits of insecticide, and $k$ is the constant of dissipation rate in days. The half-life $\left(t_{1 / 2}\right)$ 
Table 1. Typical HPLC conditions used for residue analysis of tested insecticides.

\begin{tabular}{llcc}
\hline Insecticide & \multicolumn{1}{c}{ Mobile phase } & Flow rate & Wavelength \\
\hline \multirow{2}{*}{ Abamectin } & $\begin{array}{l}\mathrm{CH}_{3} \mathrm{CN} / \mathrm{CH}_{3} \mathrm{OH} / \mathrm{H}_{2} \mathrm{O} \\
(47.5: 47.5: 5 \mathrm{v} / \mathrm{v} / \mathrm{v})\end{array}$ & 1 & $\mathrm{~mm}$ \\
Chlorpyrifos & $\mathrm{CH}_{3} \mathrm{CN} / \mathrm{H}_{2} \mathrm{O}(80: 20 \mathrm{v} / \mathrm{v})$ & 2 & 300 \\
Spinosad & $\mathrm{CH}_{3} \mathrm{CN} / \mathrm{CH}_{3} \mathrm{OH} / \mathrm{CH}_{3} \mathrm{COONH}$ & & 254 \\
\multirow{2}{*}{ Thiamethoxam } & $(60: 30: 10 \mathrm{v} / \mathrm{v} / \mathrm{v})$ & 2 & 250 \\
& $\mathrm{CH}_{3} \mathrm{CN} / \mathrm{H}_{2} \mathrm{O}(80: 20 \mathrm{v} / \mathrm{v})$ & 1 & 254 \\
\hline
\end{tabular}

was calculated from the $k$ value for each experiment using the equation: $t_{1 / 2}=\ln 2 / k$.

\section{RESULTS}

\section{Recovery and detection limits}

Recovery experiments were conducted on untreated tomato fruits fortified with two concentrations of each insecticide (0.5 and $\left.1.0 \mathrm{mg} \mathrm{kg}^{-1}\right)$. The extraction and clean-up were performed as described earlier, and then determined using HPLC-DAD. Recoveries of four tested insecticides were determined in three replicates to confirm the validity of the method. The recovery percentages and relative standard deviation (RSD) values were in the acceptable range (Table 2). The response was linear within the range of $0.1-10.0 \mathrm{mg} \mathrm{L}^{-1}$ $\left(\mathrm{R}^{2}=0.99942,99973,0.99877\right.$, and 0.99892 for abamectin, chlorpyrifos, spinosad, and thiamethoxam, respectively). The limit of detection (LOD) of the tested insecticides was 0.01 $\mathrm{mg} \mathrm{kg}-1$ and resulted by considering a signal-to-noise ratio of 3 with reference to the background noise obtained for the blank sample. The limits of quantification (LOQ) determined as the lowest concentration in tomato of a given compound giving a response that could be quantified with RSD lower than $20 \%$ was $0.05 \mathrm{mg} \mathrm{kg}^{-1}$ for all tested insecticides. These results indicated that the QuEChERS sample preparation, followed by HPLC-DAD analysis is a valid method for residue determination of the tested insecticides in tomato fruits.

Table 2. Fortified recoveries of studied insecticides in tomato fruits $(n=3)$.

\begin{tabular}{lccr}
\hline Insecticide & Spiked level & $\begin{array}{c}\text { Average } \\
\text { recovery }\end{array}$ & RSD \\
\hline \multirow{2}{*}{ Abamectin } & $\mathrm{mg} \mathrm{kg}^{-1}$ & & \\
\cline { 3 - 4 } Chlorpyrifos & 1.0 & 96.6 & 14.3 \\
& 0.5 & 102.6 & 17.0 \\
Spinosad & 1.0 & 110.2 & 1.8 \\
Thiamethoxam & 0.5 & 108.0 & 12.9 \\
& 1.0 & 98.8 & 9.2 \\
& 0.5 & 100.0 & 11.5 \\
& 1.0 & 130.0 & 5.4 \\
& 0.5 & 110.6 & 8.6 \\
\hline
\end{tabular}

RSD: Relative standard deviation.

\section{Residues of insecticides in tomato fruits under open field condition}

Dissipation rates of the four tested insecticides were studied after three applications at the recommended rates on tomato fruits under open field conditions. The residues of insecticides are shown in Table 3. The obtained results indicated that insecticide residues decreased with different day intervals after application. The initial deposits were 0.255, 4.28, 0.205, and $0.647 \mathrm{mg} \mathrm{kg}^{-1}$ for abamectin, chlorpyrifos, spinosad, and thiamethoxam, respectively. Residue levels of chlorpyrifos and thiamethoxam decreased to reach 0.326 and $0.03 \mathrm{mg} \mathrm{kg}^{-1}$ after $15 \mathrm{~d}$ from application indicating that $92.4 \%$ and $95.4 \%$ of chlorpyrifos and thiamethoxam dissipated, respectively. Abamectin and spinosad residues decreased to reach 0.1 and $0.026 \mathrm{mg} \mathrm{kg}^{-1}$ in $5 \mathrm{~d}$. Abamectin and spinosad residues were undetectable after $7 \mathrm{~d}$ of application. The kinetic equation, half-lives and coefficient $(\mathrm{R})$ of insecticide residue dissipation were calculated from the experimental data and summarized in Table 4 . The dissipation regressive equation could be described by the following equations; $C_{t}=0.2627$ $\mathrm{e}^{-0.17 \mathrm{t}}\left(R^{2}=0.86\right), \mathrm{C}_{\mathrm{t}}=3.7183 \mathrm{e}^{-0.275 \mathrm{t}}\left(R^{2}=0.9537\right), \mathrm{C}_{\mathrm{t}}=$ $0.1778 \mathrm{e}^{-0.407 \mathrm{t}}\left(R^{2}=0.9735\right), \mathrm{C}_{\mathrm{t}}=0.6074 \mathrm{e}^{-0.11 \mathrm{t}}\left(R^{2}=0.8299\right)$ for abamectin, chlorpyrifos, spinosad, and thiamethoxam, respectively. The half-life values were 4.1, 2.5, 1.7, and 6.3 d for abamectin, chlorpyrifos, spinosad, and thiamethoxam, respectively.

\section{DISCUSSION}

The results of insecticide residue analysis showed that the dissipation of insecticides follow the first order kinetics. The correlation coefficient ranged from 0.83 to 0.97 . The half-life values of four insecticides ranged from 1.7 to 4.1 d. Chlorpyrifos dissipation from tomato has been studied

Table 3. Amounts of insecticide residues detected in tomato fruit samples under open field condition.

\begin{tabular}{|c|c|c|c|c|}
\hline \multirow{2}{*}{$\begin{array}{l}\text { Interval after } \\
\text { application }\end{array}$} & \multicolumn{4}{|c|}{ Residue } \\
\hline & Abamectin & Chlorpyrifos & Spinosad & Thiamethoxam \\
\hline d & \multicolumn{4}{|c|}{$\longrightarrow \mathrm{mg} \mathrm{kg}^{-1}($ mean $\pm \mathrm{SD})$} \\
\hline 0 & $0.255 \pm 0.077$ & $4.280 \pm 0.210$ & $0.205 \pm 0.019$ & $0.647 \pm 0.137$ \\
\hline 1 & $0.206 \pm 0.086$ & $2.500 \pm 0.690$ & $0.107 \pm 0.002$ & $0.440 \pm 0.042$ \\
\hline 3 & $0.197 \pm 0.027$ & $1.460 \pm 0.170$ & $0.045 \pm 0.013$ & $0.440 \pm 0.049$ \\
\hline 5 & $0.100 \pm 0.008$ & $1.026 \pm 0.184$ & $0.026 \pm 0.029$ & $0.382 \pm 0.438$ \\
\hline 7 & nd & $0.840 \pm 0.169$ & nd & $0.370 \pm 0.183$ \\
\hline 10 & nd & $0.568 \pm 0.036$ & nd & $0.164 \pm 0.007$ \\
\hline 15 & nd & $0.326 \pm 0.284$ & nd & $0.030 \pm 0.042$ \\
\hline
\end{tabular}

nd: Not detected.

Table 4. First-order kinetic equations, half-lives, and preharvest intervals (PHI) for studied insecticides.

\begin{tabular}{llccr}
\hline Insecticide & Kinetic equation & $\mathrm{R}^{2}$ & Half-life $(\mathrm{d})$ & PHI \\
\hline Abamectin & $\mathrm{C}_{\mathrm{t}}=2627 \mathrm{e}^{-0.17 \mathrm{t}}$ & 0.8600 & 4.1 & 7 \\
Chlorpyrifos & $\mathrm{C}_{\mathrm{t}}=3.7183 \mathrm{e}^{-0.275 \mathrm{t}}$ & 0.9537 & 2.5 & 15 \\
Spinosad & $\mathrm{C}_{\mathrm{t}}=0.1778 \mathrm{e}^{-0.407 \mathrm{t}}$ & 0.9735 & 1.7 & $<1$ \\
Thiamethoxam & $\mathrm{C}_{\mathrm{t}}=0.6074 \mathrm{e}^{-0.11 \mathrm{t}}$ & 0.8299 & 6.3 & 10 \\
\hline
\end{tabular}


earlier. For example, Gupta et al. (2011) reported that chlorpyrifos residues on tomato dissipated with the half-life values ranged from 2.9 to $3.3 \mathrm{~d}$. The half-life of chlorpyrifos obtained in the study was almost the same with that reported by Al-Eed (2006). In consistent with the obtained results, Mohammadi and Imani (2012) stated that chlorpyrifos has the post-harvest period near $15 \mathrm{~d}$ in tomato fruits under greenhouse condition. In addition, Rani et al. (2013) reported that residues of chlorpyrifos dissipated with half-life period of $4.43 \mathrm{~d}$ at single dose and $4.38 \mathrm{~d}$ at double dose following pseudo first order kinetics. Residues of chlorpyrifos in both the doses on $0 \mathrm{~d}$ were below maximum residue limit (MRL) of $0.5 \mathrm{mg} \mathrm{kg}^{-1}$. The half-life value of thiamethoxam obtained in this study was comparable with those previously reported on the dissipation of thiamethoxam from tomato (Abd El-Zaher et al., 2011), transplanted paddy (Barik et al., 2010) and green tobacco leaves (Wang et al., 2013). Moreover, Karmakar and Kulshrestha (2009) reported that thiamethoxam dissipated from $82 \%$ to $87 \%$ in $10 \mathrm{~d}$ with a half-life of $4 \mathrm{~d}$ in tomato fruits and total residues reached below detectable level in $15 \mathrm{~d}$ in tomato fruits.

The results of spinosad residue analysis are in consistent with those obtained by Kashyap et al. (2015), who reported that half-life values of spinosad were determined to be 1.20 and $1.60 \mathrm{~d}$ at recommended and double the recommended dosage, respectively. The safety interval for spinosad sprayed tomato fruit was determined to be 1.92 and 3.88 $\mathrm{d}$ at application rate of 15 and $30 \mathrm{~g}$ ai ha ${ }^{-1}$, respectively. In addition, Sharma et al. (2007) studied the residues of spinosad in cauliflower and cabbage, and found that the half-lives values were 2.8 and $1.5 \mathrm{~d}$, respectively, for the $17.5 \mathrm{~g} \mathrm{ha}^{-1}$ treatment, and as 2.0 and $2.6 \mathrm{~d}$ for the $35 \mathrm{~g} \mathrm{ha}^{-1}$ treatment. Zhao et al. (2007) demonstrated that spinosyn A and $\mathrm{D}$ dissipated rapidly after application in eggplant and the half-life values of spinosyn A and D in were 1.81 and $1.61 \mathrm{~d}$, respectively. Singh and Battu (2012) reported that the initial deposit averages of spinosad in cabbage were 0.33 and 0.56 $\mathrm{mg} \mathrm{kg} \mathrm{k}^{-1}$ at single and double dosages, respectively, and the half-life values were 1.4 and $1.5 \mathrm{~d}$ at the same dosages. On the other hand, the half-life value of abamectin was $4.1 \mathrm{~d}$. This value was higher than that $(1.06 \mathrm{~d})$ described by Abd Al-Rahman et al. (2012) on the residue analysis of abamectin in tomato fruits under field conditions. However, Ahmed (2011) indicated that the half-life time for abamectin was calculated to be $3.93,6.16$, and $2.2 \mathrm{~d}$ for orange, strawberry, and cucumber, respectively. Moreover, Abdellseid and Abdel Rahman (2014) illustrated that dissipation half-life time of abamectin residues in tomato was $2.4 \mathrm{~d}$. According to maximum residue limit (MRL) $0.5 \mathrm{mg} \mathrm{kg}^{-1}$, the pre harvest interval (PHI) of abamectin on tomato was $8 \mathrm{~d}$ after the treatment.

The maximum residues level (MRL) values set by EU for abamectin, chlorpyrifos, spinosad, and thiamethoxam are $0.02,0.5,1.0$, and $0.2 \mathrm{mg} \mathrm{kg}^{-1}$, respectively (EU, 2005). Based on these MRL values, the preharvest intervals (PHIs) were $7,15,<1$, and $10 \mathrm{~d}$ for abamectin, chlorpyrifos, spinosad, and thiamethoxam, respectively.

\section{CONCLUSION}

The dissipation rates of abamectin, chlorpyrifos, spinosad, and thiamethoxam in tomato fruits were evaluated under field conditions. The obtained results indicated that tomato fruit could be safely consumed after $10,15,<1$, and $10 \mathrm{~d}$ of application for abamectin, chlorpyrifos, spinosad, and thiamethoxam according to the recommended maximum residue limit (MRL). In addition, the results showed that the bioinsecticides, abamectin, and spinosad declined rapidly and had shorter half-life values compared with the conventional insecticides, chlorpyrifos, and thiamethoxam. Therefore, it is recommended to use the bioinsecticides, in particularly spinosad, for control insects attacking tomato during harvesting times.

\section{ACKNOWLEDGEMENTS}

This work was supported by the Alexandria University Research Fund (ALEX-REP, 2010-2013).

\section{REFERENCES}

Abd Al-Rahman, S.H., M.M. Almaz, and N.S. Ahmed. 2012. Dissipation of fungicides, insecticides, and acaricide in tomato using HPLC-DAD and QuEChERS methodology. Food Analytical Methods 5:564-570.

Abdellseid, A. M., and T.A. Abdel Rahman. 2014. Residue and dissipation dynamics of abamectin in tomato fruit using QuEChERS methodology. International Conference on Food, Biological and Medical Sciences (FBMS-2014), Bangkok, Thailand.

Abd El-Zaher, T.R., I.N. Nasr, and H.A. Mahmoud. 2011. Behavior of some pesticide residues in and on tomato and kidney beans fruits grown in open field. American-Eurasian Journal of Toxicological Sciences 3:213-218.

Ahmed, K.R.A. 2011. Studies on abamectin pesticide residues in horticultural crops. MSc thesis. Department of Economic Entomology and Pesticides, Faculty of Agriculture, Cairo University, Cairo, Egypt.

Al-Eed, M.A. 2006. Determination of pirimiphos-methyl and chlorpyrifos-ethyl residues on tomato and pepper fruits grown in greenhouse. Journal of Applied Sciences 6:979-982.

Anastassiades, M., S.J. Lehotay, D. Štajnbaher, and F.J. Schenck. 2003. Fast and easy multiresidue method employing acetonitrile extraction/partitioning and "dispersive solid phase extraction" for the determination of pesticides residue in produce. Journal of AOAC International 86:412-431.

APC. 2010. Pesticides registration. Agricultural Pesticide Committee (APC), Ministry of Agriculture, Cairo, Egypt.

Barik, S.R., P. Ganguly, S.K. Kunda, R.K. Kole, and A. Bhattacharyya. 2010. Persistence behaviour of thiamethoxam and lambda cyhalothrin in transplanted paddy. Bulletin of Environmental Contamination and Toxicology 85:419-422.

Chen, C., Y. Qian, X. Liu, C. Tao, Y. Liang, and Y. Li. 2012. Risk assessment of chlorpyrifos on rice and cabbage in China. Regulatory Toxicology and Pharmacology 62:125-130.

Dorais, M., D.L. Ehret, and A.P. Papadopoulos. 2008. Tomato (Solanum lycopersicum) health components: from the seed to the consumer. Phytochemistry Reviews 7:231-250. 
EU. 2005. Regulation (EC) No 396/2005 of the European Parliament and of the council of 23 February 2005 on maximum residue levels of pesticides in or on food and feed of plant and animal origin and amending. Council Directive 91/414/ EEC Available at http://eur-lex.europa.eu/legal-content/EN/ TXT/PDF/?uri=CONSLEG:2005R0396:20121026 (accessed January 2015).

FAO. 2011. FAOSTAT. Food and Agriculture Organization of the United Nations (FAO), Rome, Italy. Available at http://faostat3. fao.org/home/E.

Fenoll, J., E. Ruiz, P. Hellín, A. Lacasa, and P. Flores. 2009. Dissipation rates of insecticides and fungicides in peppers grown in greenhouse and under cold storage conditions. Food Chemistry 113:727-732.

Garau, V.L., A. Angioni, A.G. Del Real, M. Russo, and P. Cabras. 2002. Disappearance of azoxystrobin, cyprodinil, and fludioxonil on tomato in a greenhouse. Journal of Agricultural and Food Chemistry 50:1929-1932.

Gupta, S., V.T. Gajbhiye, R.K. Sharma, and R.K. Gupta. 2011. Dissipation of cypermethrin, chlorpyriphos, and profenofos in tomato fruits and soil following application of pre-mix formulations. Environmental Monitoring and Assessment 174:337-345.

Karmakar, R., and G. Kulshrestha. 2009. Persistence, metabolism and safety evaluation of thiamethoxam in tomato crop. Pest Management Science 65:931-937.

Kashyap, L., D.C Sharma, and Anil. 2015. Dissipation behaviour of spinosad in polyhouse grown tomato under mid-hill conditions of Himachal Pradesh, India. Environmental Monitoring and Assessment 187:75.

Korycinska, A., and H. Moran. 2009. Plant pest notice: South American tomato moth, Tuta absoluta (Nr 56).p. 1-4. Department for Environment, Food and Rural Affairs, Food and Environment Research Agency, London, UK.

Liu, Y., H. Sun, and S. Wang. 2013. Dissipation and residue of spinosad in zucchini under field conditions. Bulletin of Environmental Contamination and Toxicology 91:256-259.

Malhat, F., H. Abdallah, and I. Nasr. 2012. Estimation of etofenprox residues in tomato fruits by QuEChERS methodology and HPLCDAD. Bulletin of Environmental Contamination and Toxicology 88:891-893
Mandal, K., G. Jyot, and B. Singh. 2009. Dissipation kinetics of spinosad on cauliflower (Brassica oleracea var. botrytis L.) under subtropical conditions of Punjab, India. Bulletin of Environmental Contamination and Toxicology 83:808-811.

Mohammadi, S., and S. Imani. 2012. Considering post-harvest period of chlorpyrifos insecticide on greenhouse tomatoes with the solid phase extraction method and with the help of the GC, GC/MS. Annals of Biological Research 3:1679-1682.

Mohammed, A.S. 2010. New record for leafminer, Tuta absoluta (Lepidoptera: Gelechiidae) infested tomato plantations in Kafer El-Sheikh region. Journal of Agricultural Research Kafer ElSheikh University 36:238-239.

Mohapatra, S., A.K. Ahuja, M. Deepa, G.K. Jagdish, N. Rashmi, and D. Sharma. 2010. Persistence of abamectin in eggplant (Solanum melongena). Pest Management in Horticultural Ecosystems 16:29-33.

Rani, M., S. Saini, and B. Kumari. 2013. Persistence and effect of processing on chlorpyriphos residues in tomato (Lycopersicon esculantum Mill.) Ecotoxicology and Environmental Safety 95:247-252.

Roditakis, E., D. Papachristos, and N.E. Roditakis. 2010. Current status of the tomato leafminer Tuta absoluta in Greece. OEPP/ EPPO Bulletin 40:163-166.

Sharma, A., A. Srivastava, B. Ram, and P.C. Srivastava. 2007. Dissipation behaviour of spinosad insecticide in soil, cabbage and cauliflower under subtropical conditions. Pest Management in Horticultural Ecosystems 63:1141-1145.

Singh, S., and R.S. Battu. 2012. Dissipation kinetics of spinosad in cabbage (Brassica oleracea L. var. capitata). Environmental Toxicology and Chemistry 94:319-326.

Urbaneja, A., R. Vercher, V. Navarro, F. Garcia-Mari, y J.L. Porcuna. 2007. La polilla del tomate Tuta absoluta. Phytoma España 194:16-23.

Wang, X., Z. Xiang, X. Yan, H. Sun, and Y. Li. 2013. Dissipation rate and residual fate of thiamethoxam in tobacco leaves and soil exposed to field treatments. Bulletin of Environmental Contamination and Toxicology 91:246-250.

Zhao, E., Y. Xu, M. Dong, S. Jiang, Z. Zhou, and L. Han. 2007. Dissipation and residues of spinosad in eggplant and soil. Bulletin of Environmental Contamination and Toxicology 78:222-225. 